\title{
Depression and Spiritual Experiences on Post Graduate Students:
}

\section{A Comparative Study}

\author{
Sobia Ansari ${ }^{1 *}$, Deoshree Akhouri ${ }^{2}$, R. K. Gaur ${ }^{3}$
}

\section{ABSTRACT}

Depression has become one of the alarming crises in today's fast paced society. Person suffering from depression can overcome from spiritual point of view. Spirituality is the need for findings satisfactory answers to ultimate questions about the meaning of life, illness and death. This research study investigated the relationship between spiritual experiences and depression among male and female post graduate students, to compare males and females on depression scores and to compare males and females on spiritual experiences. This study finds that that there is no significant correlation found between daily life experiences and depression among post graduate students. It was also found that female scores higher on depression as well as on spirituality.

Keywords: Depression, Spirituality, Spiritual Experiences.

Depression is one of the major health problems affecting a large number of population especially younger generations across the world. Depressed people typically have negative thoughts about themselves, their world, and the future. They experience themselves as not good enough at doing job, of no value and often feel guilty. Depression causes a pessimistic view of things. It also discourages enthusiasm and stifles ones initiatives. It may also produce despair and bring about sickness in the mind and body. Much of the time such thoughts are completely unnecessary.

However a person who is suffering from depression can overcome from a spiritual point of view. By developing spirituality one may change one's view which may allow the individual to rise above a depressed state of mind. It can lift one's right out of any depression or despair one may feel. Spirituality provides us with the right philosophy of life. It is a guide book, lead us out of darkness of ignorance and ushering us into the light of reality. Spirituality is our helpful companion in times of difficulty. It saves us from succumbing to adversely. It is the art of crises

\footnotetext{
${ }^{1}$ Research Scholar, Department of Psychiatry, Aligarh Muslim University, India

${ }^{2}$ Assistant Professor, Department of Psychiatry, Aligarh Muslim University, India

${ }^{3}$ Professor, Department of Psychiatry, Aligarh Muslim University, India

*Responding Author (c) 2016 I S Ansari, D Akhouri, R Gaur; licensee IJIP. This is an Open Access Research distributed under the terms of the Creative Commons Attribution License (http://creativecommons.org/licenses/by/2.0), which permits unrestricted use, distribution, and reproduction in any Medium, provided the original work is properly cited.
} 
management, from which we drive intellectual inspiration when in need. Everyone is in need of spirituality, whether rich or poor, powerful a powerless. Spirituality provides a man with a starting point for life. Spirituality is a word used in an abundant of contexts that man's different times in different cultures. In literature describe it using one or more of the following elements a sense of purpose, a sense of "connectedness" to self, others, a quest for wholeness, a search for hope or harmony, a belief in a higher being or beings. Spirituality typically defined as 'the need for finding satisfactory answers to ultimate questions about the meaning of life, illness and death', can help provide a framework that helps someone gain an understanding of him or herself and cope with unpleasant and unavoidable circumstances without becoming depressed. Spiritual individuals are likely to draw their strength from within themselves and therefore feel in control of themselves and their spiritual well-being.

Depression in adolescents is increasing at an alarming rate and the statistics on adolescent depressions are sobering. Studies have indicated that depression affects approximately 30-40\% of the adolescent population (Jimmerson, 2003). Among adolescents one in five suffer from depression (Ruston, Forcier and Schectman, 2002). Most recent research has confirmed that depression in children and adolescents occurs with high frequency. The point prevalence of major depression for adolescents has been estimated between 4.0 and $8.3 \%$ (Birmahar, Ryan et al.,1996). The lifetime prevalence for major depressive disorder in adolescents is between 15 and 20\% (Harrington, Rutter and Fombonne, 1996). Before adolescence, rates of depression are somewhat higher in boys but depression occurs at about twice the rate for adolescents girls as for adolescent boys (Hankin et al., 1998). Rachel E. Dew et. al, (2008) conducted research on religion, spirituality \& depression in adolescent psychiatric outpatients and found that female gender had significantly greater depressive scores. Thus, in our study we are interested to know the correlation between spirituality and depression among male and female post graduate students and which group had greater level of depression and spirituality.

\section{OBJECTIVES OF THE PRESENT STUDY}

1. To know the relationship between spiritual experiences and depression among male and female post graduate students.

2. To compare male and female on depression scores.

3. To compare male and female on daily spiritual experiences.

\section{METHODOLOGY}

\section{Sample}

Purposive sampling method was used to select the sample. The study was conducted on 90 post graduate students age range between 21 to 25 years among which 45 were males and 45 were females selected randomly from different departments of Aligarh Muslim University. 


\section{Measures}

The two scales were used:

1) Beck Depression Inventory II- This inventory was developed by Aaron Beck (1996) and was derived from the BDI. BDI-II is a self report inventory to assess the severity of depression in adults and adolescents aged 13 years and older having 21 items. The cutoffs used differ from the original scale: 0-13: minimal depression; 14-19: mild depression; 20-28: moderate depression; and 29-63: severe depression. Higher scores indicate more severe depressive symptoms.

2) Daily Spiritual Experience Scale (DSES): This scale was developed by Lynn G.Underwood and Jeanne A. Teresi (2002). This scale includes 16 items. It is used to measure a person's perception of the transcendent in daily life and his or her perception of his or her interaction with or involvement of the transcendent in life.

\section{Procedure}

The study was carried out in the Aligarh Muslim University. For collection of data, two questionnaires were individually administered on the subject one after the other with gap of 5 minutes, before that a rapport was maintained with the subject. They were requested to answer each question carefully and freely and were also assured that their responses would be kept confidential.

\section{Statistical Analysis}

t-test and correlation were used for analysis of the data.

\section{RESUTS}

\section{Table 1 showing socio demographic details of the students}

\begin{tabular}{|l|c|c|}
\hline \multicolumn{1}{|c|}{ Variables } & Number of subjects & Percentage \\
\hline Age & 35 & $38.8 \%$ \\
$21-23$ & 55 & $61.1 \%$ \\
$24-25$ & & $50 \%$ \\
\hline Gender & 45 & $50 \%$ \\
Male & 45 & \\
Female & & $8.8 \%$ \\
\hline Marital status & 8 & $91 \%$ \\
Married & 82 & $100 \%$ \\
\hline Unmarried & & \\
\hline Education & 90 & \\
PG & & \\
\hline
\end{tabular}




\begin{tabular}{|l|c|c|}
\hline Religion & & \\
Hindu & 12 & $13.3 \%$ \\
Muslim & 78 & $86.6 \%$ \\
\hline Domicile & & \\
Rural & 10 & $11.1 \%$ \\
Urban & 66 & $73.3 \%$ \\
Semi-urban & 14 & $15.5 \%$ \\
\hline Socio-economic status & 5 & \\
Low & 68 & $75.5 \%$ \\
Middle & 17 & $18.8 \%$ \\
High & & \\
\hline
\end{tabular}

Table 1 indicates that 35 (38.8\%) patients lie in the age range of 21 to 23 years and 55 (61.1\%) in the age range of 24-25 years of age, in which 8 (8.8\%) were married and 82 (91\%) were unmarried and all belong to same education group. 12 (13.3\%) belongs to Hindu religion while 78 (86.6\%) belongs to Muslim community. Most of the subjects belong to urban area (73.3\%) and to middle socioeconomic status (75.5\%).

Table 2 Showing coefficient of correlation for total sample (N)

\begin{tabular}{|c|c|c|c|}
\hline & & Depression & $\begin{array}{l}\text { Daily spiritual } \\
\text { experiences }\end{array}$ \\
\hline Depression & $\begin{array}{l}\text { Pearson Correlation } \\
\text { Sig. ( } 2 \text { tailed) } \\
\text { N }\end{array}$ & $\begin{array}{l}1 \\
- \\
90\end{array}$ & $\begin{array}{l}0.123 \\
0.250 \\
90\end{array}$ \\
\hline $\begin{array}{l}\text { Daily } \\
\text { Spiritual } \\
\text { Experiences }\end{array}$ & $\begin{array}{l}\text { Pearson Correlation } \\
\text { Sig. (2 tailed) } \\
\text { N }\end{array}$ & $\begin{array}{l}0.123 \\
0.250 \\
90\end{array}$ & $\begin{array}{l}1 \\
- \\
90\end{array}$ \\
\hline
\end{tabular}

Table 2 indicates that there is no significant correlation was found between daily life experience and depression among post graduate students

Table 3 Showing differences of male and female on Beck Depression Inventory-II

\begin{tabular}{|l|l|l|l|}
\hline Gender & Mean & SD & t-value \\
\cline { 1 - 3 } Male Depression & 16.73 & 8.31 & \multirow{2}{*}{2.302} \\
\cline { 1 - 3 } Female Depression & 21.00 & 9.24 & \\
\hline
\end{tabular}

The result given in table 3 indicates that there is a significant difference between male and female. The $t$-value was found to be $2.302(\mathrm{p}=0.01)$. 
Table 4 Showing differences of male \& female on Daily Spiritual Experience Scale

\begin{tabular}{|l|l|l|l|}
\hline Gender & Mean & SD & t-value \\
\cline { 1 - 3 } Male DSE & 40.13 & 8.90 & \multirow{2}{*}{3.52} \\
\cline { 1 - 3 } Female DSE & 33.333 & 9.37 & \\
\hline
\end{tabular}

The result given in table 4 indicate that there is a significant difference between male and female on spirituality .The t-value was found to be $3.52(\mathrm{p}=0.01)$

\section{DISCUSSION}

The main objectives of the study is to understand the roles of Daily Spiritual Experience (DSE) in enhancing psychological and social well being among male and female post graduate students. Table 1 showing sociodemographic details of the students and found that there is no significant difference between male and female. The results given in table 2 indicate no significant correlation. However, the trend of mean scores indicates that in our sample participants usually has moderate daily spiritual experience and mild depression. This finding is further collaborated by similar researches that studied spirituality and quality of life concluded that spiritual factor appear to related overall physical health but found no relationship to mental components of health ( Thorensen and Harris, 2002). The reason for having no relationship between DSE and depression might be at a large chunk of studies as being carried out on elderly people but very few are conducted on youth and adolescents.

The obtained result in table 3 demonstrates that on depression female subjects scored higher as compared to males. This finding may be supported by a critical model given by Jill $\mathrm{M}$. Cyronowski et al.,(2000), according to this model, by 15 year of female are approximately twice as likely as male to have experienced an episode of depression and this gender gap persist for the next 35 to 40 years of age. The explanation for this gender gap was given in the light of social and hormonal mechanisms that stimulate affiliated needs for female at puberty. When female reaches puberty there there is heightened affiliative need which can create a depressogenic diathesis. This gender- linked vulnerability explains why adolescents females are more likely than males to become depressed when faced with positive life events with interpersonal consequences. Another study was conducted by Gitanjali saluja (2004) to determine the prevalence, risk factor, and risk behavior associated with depressive symptoms is a nationally representative, cross-sectional sample of young adolescents and found that $18 \%$ of youths reported symptoms of depression, a higher proportion of females (25\%) reported depressive symptoms than males (10\%) prevalence of depressive symptoms increased by age for both male and female.

Another objective of the study was to identify and compare spirituality between male and female post graduate students. The findings of the table 4 again indicate that female participants scores higher on spiritual experiences than male participants. This finding was also supported by Alethea Desrosiers and Lisa Miller (2007) who studied relational spirituality and depression in 


\section{Depression and Spiritual Experiences on Post Graduate Students: A Comparative Study}

adolescent girls. They found that depression and spirituality were higher in girls as compared with boys. This study supports our findings.

The plausible explanation for the male participants having low depression and low spiritual is because of the differences in the male and female perception of the events. Female usually develops sense of responsibility and perceived life events as threatening. On the contrary male at the same age are not so vulnerable to stress as women. The women higher mean score on depression and on spiritual experience indicate that women respond more negatively and seriously towards stressful life events as compared to men. Therefore female adapt more appropriate self talk and have faith on God and seek guidance through their religion placing the source of control outside of themselves. Thus, this external locus of control can exacerbate feelings of helplessness and depression amongst them.

Thus, the above finding indicates the potential of DSE acts as a stress buffer is reinforced by the positive association with psychosocial variables such as optimism and positive effect and the negative association with perceived stress. However, more recent studies also indicate that the relationship between religion/spirituality and depression will be more complex as all religious beliefs are not necessarily related to better mental health. The relationship between spirituality and depression affected by such factors such as race, sex and types of religious coping. Moreover, in the further study effort should be made to use measures religious of religious coping to understand how the individual is making use of religion to understand and deal with stressors. Since, very few studies had specifically addressed the relationship between spirituality and depression, a considerable large sample is needed to substantial the association between spirituality and the prevalence of depressive illness particularly in children and adolescents.

\section{CONCLUSION AND SUGGESTIONS}

The present research was conducted to assess Depression and Daily spiritual Experience among male and female post graduate students. Results showed no significant relationship between depression and spiritual experiences among male and female post graduate students. Findings of the study further showed that there was a significant difference between male and female on depression and daily spiritual experiences.

There are certain limitations of this study including small sample size and limited number of scales were used. In further research study these limitations should be overcome by taking large sample and more standard scales.

\section{REFERENCES}

Beck AT, Steer RA and Brown GK (1996) “ Manual for the Beck Depression Inventory- II”. San Antoxio, TX: Psychological Corporation.

Birrnaher, B. Ryan, S.W., Williamson, D., Brent, D., Kaufman, J. R., Perel, J., \& Nelson, B (1996). Childhood and adolescent depression; A review of the past 19 year. Part I. J Amer Acd. Child Adoles. Psychiat. 35, 1427039. 
Desrosiers A., Miller L.(2007) : Relational Spirituality \& Depression in Adolescent Girls : J Clin Psychol. volume 63-Issue 10-pages 1021-1037.

Dew E.R. et. al.(2008) : Religion, Spirituality \& Depression in Adolescent Psychiatric Outpatients. Journal of Nervous \& Mental Disease, volume 196-issue 3- pp 247-251

Hankin ,B.L. Abramson, L.Y., Moffitt. T.E. Silva, P.A., Mcgee R., \& Angell, K.E (1998) (1994). Development of depression from preadolescence to young adulthood. Emerging gender differences in a 10 year longitudinal study. JR. , Psychosocial risk factors for future adolescent suicide attempts. J. Cons. Clin Psychol. 62, 29

Harrington, R. Rutter, M., \& Fombonne, E.(1996) Development Pathways in depression. Multiple meaning antecedents, and end points Develop. Psychopath., 8, 601-16.

Jimerson, S.(2003). Depression and Anxiety in Childhood and Adolescence: Identification, Intervention and Prevention. http://www.education.ucsb.edu/Jimerson/ FeaturedConferencePresentations/SRJ_Depression_Intl_NASP_03.pdf (dated February 15th, 2004).

Ruston, J.L., Forcier, M., \& Schectman, R.M(2002). Epidemiology of depressive symptoms in the National Longitudinal Study of Adolescent Health. Journal of American and child Adolescent Psychiatry, 41, 199-205.7-305. .

Saluja G., et al.(2004). Prevalence of and Risk Factors for Depressive Symptoms Among Young Adolescents. Arch Pediatr Adolesc Med.; 158: 760-765.

Thorenson CE, Harris Ah(2002). Spirituality and health: what's the evidence and what's needed?Annals of Behavioral Medicine; 24:3-13.

Underwood, L. G.; Teresi, J. A. (2002). The Daily Spiritual Experience Scale: Development, theoretical description, reliability, exploratory factor analysis, and preliminary construct validity using health related data. Ann. Behav. Med., 24, 22-33. 